\title{
MENINGKATKAN MINAT BELAJAR SISWA MELALUI PEMANFAATAN MEDIA BELAJAR BERBASIS ANDROID MENGGUNAKAN MIT APP INVENTOR
}

\author{
Habib Ratu Perwira Negara ${ }^{1 *}$, Syaharuddin $^{2}$, Kiki Riska Ayu Kurniawati ${ }^{3}$, Vera Mandailina4, \\ Farah Heniati Santosa ${ }^{5}$
${ }^{1 *}$ Teknik Informatika, Universitas Bumigora Mataram, Kota Mataram, Indonesia, ${ }^{3}$ Tadris Matematika, UIN Mataram, Kota Mataram, Indonesia ${ }^{5}$ Pendidikan Matematika, UNW Mataram, Kota Mataram, Indonesia
${ }^{*}$ Corresponding author :
1*habib.ratu27@gmail.com, syaharuddin.ntb@gmail.com², kikirak0627@gmail.com³ vrmandailina@gmail.com ${ }^{4}$, farah.hs@gmail.com ${ }^{5}$ \\ ${ }^{2,4}$ Pendidikan Matematika, Universitas Muhammadiyah Mataram, Kota Mataram, Indonesia
}

\section{Diterima 23 Mei 2019, Disetujui 28 Mei 2019}

\begin{abstract}
ABSTRAK
Kegiatan ini bertujuan untuk meningkatkan minat belajar matematika siswa dengan menggunakan Teknologi Informasi dan Komunikasi (TIK) khususnya Smartphone dalam bentuk aplikasi android. Tim pengabdian membuat media pembelajaran berbasis Android menggunakan Mit App Inventor sebanyak 36 media, metode pada pelatihan ini dengan cara sosialisasi kepada siswa SMP/MTs di Lombok Barat dengan melibatkan beberapa mahasiswa sebagai tutor sebaya. Hasil yang diperoleh, para peserta sangat antusias dalam mengikuti kegiatan, hal tersebut ditunjukkan dengan banyaknya peserta yang bertanya, dan mencoba media pembelajaran yang telah dikembangkan, serta semangat yang ditunjukkannya dalam mempresentasikan hasil skor yang diperoleh dari quis pada setiap media pembelajarannya.
\end{abstract}

Kata kunci : Pelatihan, Media Pembelajaran, android, Mit App Inventor

\begin{abstract}
This service activity aims to increase students' interest in learning mathematics by using Information and Communication Technology (ICT), especially smartphones in the form of android applications. The service team made Android-based learning media using Mit App Inventor as many as 36 media, the method in this training was by disseminating information to junior / MTs students in West Lombok by involving several students as peer tutors. The results obtained, the participants were very enthusiastic in participating in the activity, it was shown by the number of participants who asked, and tried the learning media that had been developed, and the enthusiasm shown in presenting the results of scores obtained from quiz on each learning medium.
\end{abstract}

Keywords: Training, Learning Media, Android, Mit App Inventor

\section{PENDAHULUAN}

Proses pembelajaran yang bersifat konvensional dirasa kurang menyenangkan dan terbilang monoton. Selain itu, pembelajaran yang hanya berpusat pada guru dan buku akan membuat siswa bosan dengan pembelajaran di kelas. Oleh karena itu, diperlukan suatu inovasi pembelajaran salah satunya dengan pembelajaran yang berbasis teknologi agar tampilan dan gaya belajar lebih menarik serta membuat siswa terhindar dari rasa jenuh dan bosan saat mengikuti pembelajaran.

Semakin meningkatnya siswa yang memiliki dan menggunakan perangkat mobile maka semakin besar peluang penggunaan perangkat teknologi dalam pendidikan. Media pembelajaran yang memanfaatkan teknologi mobile learning merupakan salah satu alternatif pengembangan media pembelajaran yang inovatif. Dewasa ini, informasi dan teknologi memengaruhi aktivitas sekolah dengan sangat masif. Informasi dan pengetahuan baru menyebar dengan mudah dan aksesibel bagi siapa saja yang membutuhkannya. Pendidikan mengalami disrupsi yang sangat hebat sekali. Peran guru yang selama ini sebagai satu-satunya penyedia ilmu pengetahuan sedikit banyak bergeser menjauh darinya. Di masa mendatang, peran dan kehadiran guru di ruang kelas akan semakin menantang dan membutuhkan kreativitas yang sangat tinggi.

Penggunaan Teknologi Informasi dan Komunikasi (TIK) khususnya Smartphone dalam pembelajaran matematika di tingkat SMP/MTS mampu menyajikan media dalam bentuk aplikasi android. Saat ini pemanfaatan smartphone sebagai media pembelajaran matematika masih 
jarang diterapkan di sekolah, karena belum banyak inovasi. Oleh karena itu, tim pengabdian membuat media pembelajaran berbasis Android menggunakan Mit App Inventor sebanyak 36 media. Mit App Inventor adalah sebuah aplikasi builder untuk membuat aplikasi yang berjalan di sistem aplikasi Android yang disediakan oleh googlelabs dan untuk membuat aplikasi android haruslah bermodelkan koneksi internet dan browser. Kemudian media tersebut disosialisasikan kepada siswa MTs di Lombok Barat dengan melibatkan beberapa mahasiswa sebagai tutor sebaya untuk melatih penggunaan media tersebut. Tim Abdimas berharap memanfaatkan media tersebut akan meningkatkan minat belajar matematika siswa.

\section{METODE PELAKSANAAN}

Pengabdian ini dilaksanakan di MTs Putri AlIshlahuddin pada bulan April 2019. Adapun subjek pengabdian terdiri dari beberapa wakil dari kelas VII dan VIII sebanyak 35 siswa. Adapun prosedur pelaksanaan pengabdian sebagai berikut:

1. Melakukan koordinasi dengan pihak sekolah yang dalam hal ini adalah MTs Putri Al-Ishlahuddin.

2. Membuat jadwal pelaksanaan kegiatan sosialisasi

3. Menyiapkan perangkat termasuk alat dan bahan yang digunakan saat penyampaian dan simulasi media pembelajaran di kelas

4. Melakukan sosialisasi media pembelajaran di kelas VII dan VIII.

5. Melakukan evaluasi terhadap kemampuan siswa dari hasil simulasi media pembelajaran

6. Melakukan evaluasi dan tindaklanjut terhadap hasil pengabdian.

\section{HASIL DAN PEMBAHASAN}

\section{Daftar Media Android}

Tim pengabdian telah mengembangkan 36 media pembelajaran berbasis android, namun dalam tahapan sosialisasi yang dilakasanakan hanya 7 media yang diberikan kepada siswa dikarenakan waktu pelaksananaan yang disesuaikan dengan jadwal kegiatan sekolah yang bergitu padat. Tujuh media yang telah disosialisasikan dikelompokkan berdasarkan bidang Matematika yang dipelajari oleh siswa di sekolah, adapun media tersebut disajikan pada table berikut ini.
Tabel 1. Bidang, Materi dan Nama Aplikasi Android

\begin{tabular}{|c|c|c|c|}
\hline $\begin{array}{l}\mathrm{N} \\
\mathrm{O}\end{array}$ & Bidang & Materi & $\begin{array}{l}\text { Nama } \\
\text { Aplikasi }\end{array}$ \\
\hline 1 & Aljabar & $\begin{array}{ll}\text { 1. } & \text { Sistem } \\
& \text { Persam } \\
& \text { aan } \\
& \text { Linier } \\
& \text { Dua } \\
& \text { Variabel } \\
\text { 2. } & \text { Fungsi } \\
\text { 3. } & \text { Aritmati } \\
& \text { ka } \\
& \text { Sosial } \\
\end{array}$ & 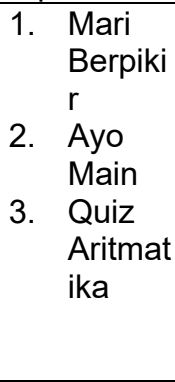 \\
\hline 2 & $\begin{array}{l}\text { Geome } \\
\text { tri }\end{array}$ & $\begin{array}{ll}\text { 1. } & \text { Teorem } \\
& \text { a } \\
& \text { Phytag } \\
& \text { oras } \\
\text { 2. } & \text { Lingkar } \\
& \text { an } \\
\text { 3. } & \text { Bangun } \\
& \text { Ruang } \\
& \text { Sisi } \\
& \text { Data } \\
\end{array}$ & $\begin{array}{ll}\text { 1. } & \text { Ayo } \\
& \text { Bermai } \\
& \mathrm{n} \\
\text { 2. } & \text { Lingkar } \\
& \text { an } \\
\text { 3. } & \text { Mari } \\
& \text { Belajar } \\
\text { dan } \\
\text { Bermai } \\
\mathrm{n}\end{array}$ \\
\hline 3 & Statistik & Statistik & Statistik \\
\hline
\end{tabular}

\section{Pelaksanaan}

Proses pelakasanaan sosuialisai ini, dibantu oleh mahasiswa dalam menjelaskan tujuan dan penggunaan aplikasi yang dikembangkan. Siswa di bagi menjadi beberapa kelompok kecil sebanyak 5 orang siswa dan setiap kelompok didampingi oleh satu mahasiswa sebagau tutor sebaya. Kegiatan pada setiap kelompok terbagai menjadi tiga kegiatan yaitu

a. Penjelasan mengenai tujuan dan cara penggunaan aplikasi media pembelajaran yang telah dikembangkan.

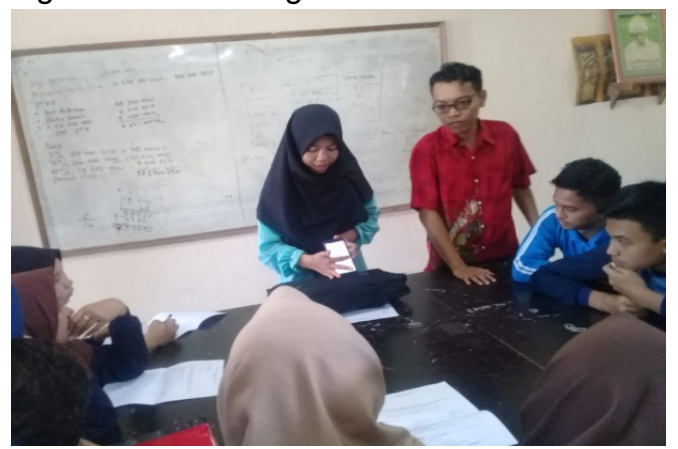

b. Siswa pada setiap kelompok diberikan waktu dalam menggunakan aplikasi yang telah dikembangkan, baik berupa mempelajari materi yang disajikan, mengerjakan latihan sampai menjawab quit pada aplikasi tersebut. 


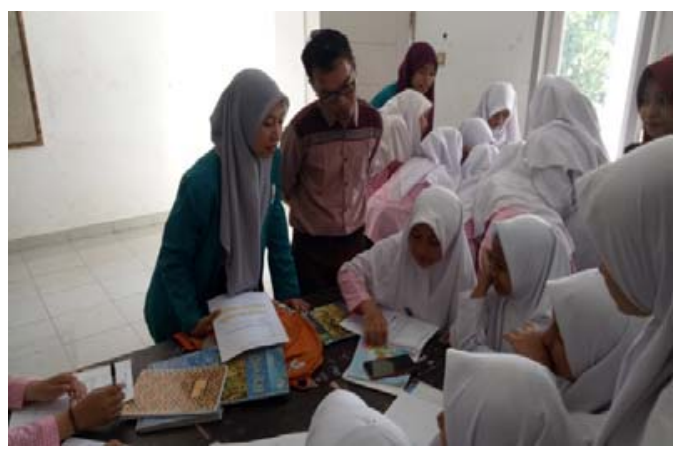

c. Siswa diberikan anget mengenai respon dalam penggunaan aplikasi media yang telah dikembangkan sebagai bentuk masukan dalam memperbaiki kualiatas aplikasi tersebut.

\section{Hasil Sosialisasi}

Hasil sosialisasi yang dilakukan tidak lain untuk melihat bagaimana minat siswa dalam belajar Matematika dengan menggunakan Teknologi Informasi dan Komunikasi (TIK) khususnya Smartphone berbasis android. tingginya minat siswa dalam belajar matematika dapat dilihat dari sangat antusiasnya siswa dalam mengikuti setiap kegiatan yang dilaksanakan serta tingginya skor quis yang diperoleh siswa pada setiap aplikasi yang digunakan. Kegiatan ini dilakukan pada siswa Ponpes Al-Ishlahuddiny Kediri kelas VII dan Kelas VIII, adapun hasil skor quis disajikan pada table 2 berikut ini.

Tabel 2. Hasil Uji Siswa Kelas VII

\begin{tabular}{|c|c|c|}
\hline $\begin{array}{c}\text { Nama } \\
\text { Aplikasi }\end{array}$ & Siswa & $\begin{array}{c}\text { Rerata } \\
\text { Skor }\end{array}$ \\
\hline \multirow{5}{*}{ Mari Berpikir } & Siswa 1 & 95 \\
\hline & Siswa 2 & 88 \\
\hline & Siswa 3 & 85 \\
\hline & Siswa 4 & 83 \\
\hline & Siswa 5 & 72 \\
\hline \multirow{5}{*}{ Ayo Main } & Siswa 1 & 84 \\
\hline & Siswa 2 & 91 \\
\hline & Siswa 3 & 81 \\
\hline & Siswa 4 & 86 \\
\hline & Siswa 5 & 86 \\
\hline \multirow{4}{*}{$\begin{array}{c}\text { Quiz } \\
\text { Aritmatika }\end{array}$} & Siswa 1 & 96 \\
\hline & Siswa 2 & 95 \\
\hline & Siswa 3 & 94 \\
\hline & Siswa 4 & 88 \\
\hline
\end{tabular}

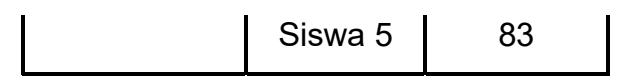

Tabel 3. Hasil Uji Siswa Kelas VIII

\begin{tabular}{|c|c|c|}
\hline $\begin{array}{c}\text { Nama } \\
\text { Aplikasi }\end{array}$ & Siswa & $\begin{array}{c}\text { Rerata } \\
\text { Skor }\end{array}$ \\
\hline \multirow{5}{*}{ Ayo Bermain } & Siswa 1 & 91 \\
\hline & Siswa 2 & 84 \\
\hline & Siswa 3 & 86 \\
\hline & Siswa 4 & 79 \\
\hline & Siswa 5 & 64 \\
\hline \multirow{5}{*}{ Lingkaran } & Siswa 1 & 94 \\
\hline & Siswa 2 & 92 \\
\hline & Siswa 3 & 78 \\
\hline & Siswa 4 & 94 \\
\hline & Siswa 5 & 87 \\
\hline \multirow{5}{*}{ Statistik } & Siswa 1 & 83 \\
\hline & Siswa 2 & 79 \\
\hline & Siswa 3 & 86 \\
\hline & Siswa 4 & 91 \\
\hline & Siswa 5 & 69 \\
\hline \multirow{5}{*}{$\begin{array}{l}\text { Mari Belajar } \\
\text { dan Bermain }\end{array}$} & Siswa 1 & 71 \\
\hline & Siswa 2 & 86 \\
\hline & Siswa 3 & 81 \\
\hline & Siswa 4 & 87 \\
\hline & Siswa 5 & 89 \\
\hline
\end{tabular}

Berdasarkan hasil tabel 2 dan tabel 3 di atas dapat kita hitung rata-rata setiap aplikasi untuk melihat bagaimana respon siswa terhadap media yang telah dikembangkan. Berdarakan table 2 Diperoleh rata untuk media "Mari Berpikir" adalah 84.6, media "ayo main" adalah 84.6, dan media Quiz Aritmatika adalah 91.5. sedangkan pada table 3 diperoleh rata-rata untuk media "ayo bermain" adalah 84, media "lingkaran" adalah 89, media "Statistik" 82.8, dan media "Mari Belajar dan Bermain" adalah 81.6. Hasil ini cukup menggambarkan tingginya minat siswa dalam belajar Matematika.

\section{Respon Siswa Terhadap Media}

Setelah kami melakukan simulasi media pembelajaran, kemudian untuk kepentingan pengembangan selanjutnya, tim melakukan 
verifikasi kepada peserta (siswa) terkait media tersebut dengan memberikan angket. Berdasarkan hasil angket, terdapat beberapa item pada media yang masih kurang menarik dan optimal seperti:

a. Aspek Tampilan. Beberapa siswa mengatakan belum optimal pada: (1) kesesuaian pemilihan gambar animasi dengan materi, kemenarikan tampilan tombol (button), (3) kesesuaian pemilihan background; (4) kesesuaian pemilihan ukuran dan jenis huruf

b. Aspek Materi. Beberapa siswa mengatakan belum optimal pada: (1) kejelasan isi materi (termasuk SK, KD, indikator), (2) kesesuaian bahasa dengan sasaran pengguna, runtutan Soal evaluasi yang disajikan, (4) keseimbangan soal latihan/tes evaluasi dengan materi.

\section{SIMPULAN}

Kegiatan pengabdian ini berjalan dengan baik dan lancer, terlihat dari aktivitas siswa dalam mengoperasikan aplikasi berbasis android. Di samping itu, nilai kemampuan siswa kelas VII dalam menjawab soal quis yang ada di aplikasi sebesar 87,13 yang berarti "sangat baik", sedangkan kemampuan siswa kelas VIII sebesar 83,55 yang berarti "sangat baik" pula. Dari hasil ini, kami menyimpulkan bahwa seluruh siswa berhasil dalam menguasai media android yang telah dilatih dan terjadi peningkatan pada minat belajar siswa.

\section{UCAPAN TERIMA KASIH}

Tim peneliti mengucapkan terima kasih kepada berbagai pihak di antaranya LP2M Universitas Bumigora Mataram yang telah mendukung penuh kegiatan pengabdian ini, Kepala MTs Putri Al Ishlahuddin yang telah memberikan izin sehingga pengabdian kepada masyarakat ini bisa terlaksana. Terima kasih juga tidak lupa kami sampaikan kepada semua guru dan mahasiswa yang telah ikut berpartisifasi dalam kegiatan pengabdian ini, besar harapan kami mudah-mudahan relasi dan kerjasama di bangun dalam pengabdian ini bisa berkelanjutan dalam pengadian-pengadian yang lain guna memajukan kualitas pendidikan di Indonesia.

\section{DAFTAR PUSTAKA}

Hamdan Husein Batubara. (2017). Pengembangan Media Pembelajaran Matematika Berbasis Android Untuk Siswa SD/MI. Jurnal Madrasah Ibtidaiyah, 3(1), 12-27
Imam Hambali, M. J. Dewiyani Sunarto, Teguh Sutanto. (2013). Rancang Bangun Aplikasi Pembelajaran Aksara Jawa Berbasis Android. Jurnal JSIKA, 2(2), 106-112

L, S. M. (2006). Active Learning. Bandung: Nusamedia.

Nurseto, T. (2011). Membuat Media Pembelajaran yang Menarik. Jurnal Ekonomi \& Pendidikan, 8(1), 1-12

Ratih Wulandari, Herawati Susilo, Dedi Kuswandi. (2017). Penggunaan Multimedia Interaktif Bermuatan Game Edukasi Untuk Meningkatkan Aktivitas Dan Hasil Belajar Siswa Sekolah Dasar. Jurnal Pendidikan, 8(2), 1024-1029

Syah, M. (2007). Psikologi Pendidikan dengan Pendekatan Baru. Bandung: Rordakarya.

Satria Adhi Kusuma Marhadini, dkk. (2017). Pengembangan Media Pembelajaran Berbasis Android pada Materi Gerak Parabola Untuk Siswa SMA. UPEJ Unnes Physics Education Journal, 6(3), 38-43 